\title{
Insufficiency of DNA repair enzyme ATM promotes naive CD4 T-cell loss in chronic hepatitis $C$ virus infection
}

\author{
Juan Zhao ${ }^{1,2}$, Xindi Dang ${ }^{1,2}$, Peixin Zhang ${ }^{3}$, Lam Nhat Nguyen ${ }^{1,2}$, Dechao Cao ${ }^{1,2}$, Lin Wang ${ }^{1,2}$, Xiaoyuan Wu W $^{1,2}$, \\ Zheng D Morrison ${ }^{1,2}$, Ying Zhang ${ }^{3}$, Zhansheng Jia ${ }^{3}$, Qian Xie ${ }^{1,4}$, Ling Wang ${ }^{1,2}$, Shunbin Ning ${ }^{1,2}$, Mohamed EL Gazzar ${ }^{1,2}$, \\ Jonathan P Moorman ${ }^{1,2,5}$ and Zhi Q Yao ${ }^{1,2,5}$
}

\begin{abstract}
T cells have a crucial role in viral clearance and vaccine response; however, the mechanisms regulating their responses to viral infections or vaccinations remain elusive. In this study, we investigated T-cell homeostasis, apoptosis, DNA damage, and repair machineries in a large cohort of subjects with hepatitis $\mathrm{C}$ virus (HCV) infection. We found that naive CD4 T cells in chronically HCV-infected individuals (HCV T cells) were significantly reduced compared with agematched healthy subjects. In addition, HCV T cells were prone to apoptosis and DNA damage, as evidenced by increased 8-oxoguanine expression and $\mathrm{HH} 2 \mathrm{AX} / 53 \mathrm{BP} 1$-formed DNA damage foci-hallmarks of DNA damage responses. Mechanistically, the activation of DNA repair enzyme ataxia telangiectasia mutated (ATM) was dampened in HCV T cells. ATM activation was also diminished in healthy T cells exposed to ATM inhibitor or to HCV (core protein) that inhibits the phosphoinositide 3 kinase pathway, mimicking the biological effects in HCV T cells. Importantly, ectopic expression of ATM was sufficient to repair the DNA damage, survival deficit, and cell dysfunctions in HCV T cells. Our results demonstrate that insufficient DNA repair enzyme ATM leads to increased DNA damage and renders HCV T cells prone to apoptotic death, which contribute to the loss of naive T cells in HCV infection. Our study reveals a novel mechanism for T-cell dysregulation and viral persistence, providing a new strategy to improve immunotherapy and vaccine responses against human viral diseases.
\end{abstract}

\section{Introduction}

Hepatitis $\mathrm{C}$ virus $(\mathrm{HCV})$ is a blood-born pathogen characterized by a high rate $(>80 \%)$ of chronic infection, which can progress to liver cirrhosis and hepatocellular

\footnotetext{
Correspondence: Zhi Q Yao (yao@etsu.edu)

${ }^{1}$ Center of Excellence in Inflammation, Infectious Disease and Immunity, James $\mathrm{H}$ Quillen College of Medicine, East Tennessee State University, Johnson City, TN 37614, USA

${ }^{2}$ Department of Internal Medicine, Division of Infectious, Inflammatory and Immunologic Diseases, Quillen College of Medicine, ETSU, Johnson City, TN 37614, USA

${ }^{3}$ Department of Infectious Diseases, Tangdu Hospital, the Fourth Military Medical University, Xi'an 710038, China

${ }^{4}$ Department of Biomedical Science, James $\mathrm{H}$ Quillen College of Medicine, East Tennessee State University, Johnson City, TN 37614, USA

${ }^{5}$ Department of Veterans Affairs, Hepatitis (HCV/HIV) Program, James H Quillen VA Medical Center, Johnson City, TN 37614, USA
}

carcinoma-a leading cause for liver transplantation ${ }^{1}$. Notably, HCV has evolved numerous strategies to evade host immunity and harness virus persistence ${ }^{1}$, providing an excellent model to study the mechanisms of virusmediated host immune dysfunction in humans. We and others have previously reported that patients with chronic $\mathrm{HCV}$ infection exhibit premature T-cell aging, as demonstrated by overexpression of aging markers and telomere attrition-indicating excessive proliferative turnover or inadequate telomeric maintenance ${ }^{2-6}$. However, the molecular mechanisms that control $\mathrm{T}$-cell homeostasis and virus persistence in humans remain unclear.

T-cell homeostasis is tightly controlled, requiring a fine balance between influx of newly generated $\mathrm{T}$ cells from the

\section{(c) The Author(s) 2018}

(c) (i) Open Access This article is licensed under a Creative Commons Attribution 4.0 International License, which permits use, sharing, adaptation, distribution and reproduction c. in any medium or format, as long as you give appropriate credit to the original author(s) and the source, provide a link to the Creative Commons license, and indicate if changes were made. The images or other third party material in this article are included in the article's Creative Commons license, unless indicated otherwise in a credit line to the material. If material is not included in the article's Creative Commons license and your intended use is not permitted by statutory regulation or exceeds the permitted use, you will need to obtain permission directly from the copyright holder. To view a copy of this license, visit http://creativecommons.org/licenses/by/4.0/. 
thymus and efflux by consumption via T-cell apoptosis, and self-replication within the existing pools of T lymphocytes ${ }^{7}$, ${ }^{8}$. With deficient thymic influx in aging adults, the immune system responds to in vivo and in vitro challenges by expanding existing $\mathrm{T}$ cells, leading to increased proliferative turnover, telomere attrition, and cell apoptosis ${ }^{7},{ }^{8}$. We hypothesize that premature T-cell aging not only involves virus-specific effector and memory $\mathrm{T}$ cells engaging in chronic viral infection, but may also extend to the compartment of naive $\mathrm{T}$ cells that are unprimed by antigens. In support of this notion, broad regulatory anomalies, including the markers for $\mathrm{T}$-cell exhaustion and senescence, are found not only expressed on virus-specific $\mathrm{T}$ cells, but also on unprimed naive $\mathrm{T}$ cells that have not yet engaged in immune responses ${ }^{2-6}, 9-14$. This notion is also supported by the observations that individuals with chronic viral (HCV or HIV) infection often have blunted vaccine responses, suggesting a broad and shared mechanism of immune dysregulation, particularly naive CD4 T-cell dysfunction, and vaccine non-responsiveness in virally infected individuals $^{2,3,15-19}$.

Human naive $\mathrm{T}$ cells have a relatively long life span (150 160 days) and thus are exposed to a multitude of genotoxic stressors, leading to $1 \%$ of a pool of 300 billion $\mathrm{T}$ cells to be replaced daily ${ }^{7,8}$. Notably, naive $\mathrm{T}$ cells are typically resistant to death receptor/ligand (Fas/Fas-L)mediated apoptosis, pointing toward cell-internal signals as apoptosis initiators ${ }^{20}$. One of the internal stressors linked to apoptosis is damaged DNA, which is particularly important in senescent cells that have been chronically exposed to the endogenously generated reactive oxygen species $(\mathrm{ROS})^{21}$. To maintain genomic stability and cell survival, cells continuously recognize and respond to this DNA damage, which will either activate DNA damage checkpoints to arrest cell cycle progression and allow for repair or, if the damaged DNA is beyond repair, undergo apoptosis $^{22}$.

A major sensor of DNA breaks is the MRN complex (MRE11, RAD50, and NBS1), which subsequently recruits the protein kinase ataxia telangiectasia mutated (ATM), an enzyme critically involved in repairing DNA doublestrand breaks (DSBs) for cell survival ${ }^{23}$, 24 . ATM was originally identified in individuals with ataxia telangiectasis, an autosomal recessive disorder exhibiting progressive ataxia, telangiectasia, immunodeficiency, genome instability, and cancer predisposition ${ }^{25}$. ATM, accompanied by ataxia telangiectasia Rad3-related (ATR) and DNA-dependent protein kinase catalytic subunit c (DNA-PKc), is the pinnacle kinase of the DNA repair signaling cascade, and belongs to the phosphoinositide 3 kinase (PI3K)-related kinase family ${ }^{26}$. Accumulation of DNA-DSBs activates ATM cascades, along with other DNA damage repair machineries, which are important for DNA reprogramming and cell remodeling.
To identify factors that perturb T-cell homeostasis during $\mathrm{HCV}$ infection, we investigated the mechanism that controls T-cell survival and DNA damage repair capabilities in primary $\mathrm{CD} 4 \mathrm{~T}$ cells. We demonstrate that insufficiency of ATM leads to accumulation of DNA damage, rendering naive $\mathrm{CD} 4 \mathrm{~T}$ cells sensitive to apoptosis and T-cell loss, contributing to viral persistence and vaccine non-responsiveness in chronic $\mathrm{HCV}$ infection.

\section{Results \\ Naive CD4 T-cell apoptosis and loss in HCV-infected patients}

As an initial approach to identify factors that perturb Tcell homeostasis in $\mathrm{HCV}$ infection, we characterized the frequencies of primary $\mathrm{T}$ cells and their survival rate or susceptibility to apoptosis in individuals with chronic HCV infection $(n=68)$ versus age-matched healthy subjects (HS) $(n=38)$. We first analyzed total $\mathrm{CD}^{+}$, $\mathrm{CD} 4 \mathrm{RA}^{+} \mathrm{CD}^{+}$(naive), and $\mathrm{CD} 45 \mathrm{RA}^{-} \mathrm{CD} 4^{+}$(memory) $\mathrm{T}$-cell frequencies in the peripheral blood mononuclear cells (PBMCs) using flow cytometry. As shown in Fig. 1a (representative dot plots and summary data), while the total CD4 T-cell numbers in PBMCs were slightly lower in $\mathrm{HCV}$ patients, the compartment of naive CD4 T cells was significantly reduced $(P<0.0001)$, whereas memory CD4 T cells were expanded in chronically $\mathrm{HCV}$-infected subjects compared to HS. To exclude the possibility that the gated PBMCs may include some CD4-expresing monocytes, we further gated on $\mathrm{CD}^{+}{ }^{+} \mathrm{T}$ cells, followed by analyzing $\mathrm{CD}_{4} 5 \mathrm{RA}^{+} \mathrm{CD}^{+} \mathrm{CD}^{+}$(naive) and $\mathrm{CD}_{4} 5 \mathrm{RA}^{-} \mathrm{CD}^{+} \mathrm{CD}^{+}$(memory) $\mathrm{T}$-cell populations, which produced similar results; i.e., chronic HCV subjects exhibited a significant contraction of naive T-cell pools and expansion of memory $\mathrm{T}$ cells in their peripheral blood (data not shown). Notably, the loss of naive CD4 T cells from chronically $\mathrm{HCV}$-infected subjects did not correlate with HCV genotype, viral load, or hepatic transaminase levels (data not shown). This observation is in line with the previous reports showing a reduced naive CD4 T-cell number-reflecting a state of immune activation and exhaustion in patients with chronic HCV infection ${ }^{9,} 10$.

Apoptosis represents a major mechanism controlling Tcell homeostasis in adults ${ }^{7}$. The vast majority of CD4 $\mathrm{T}$ cells in vivo are in a resting state and, accordingly, do not undergo apoptosis. When removed from their natural resources and kept ex vivo, human $\mathrm{T}$ cells spontaneously and progressively go through the programmed cell death (spontaneous apoptosis). To explore whether apoptosis contributes to the naive T-cell loss in $\mathrm{HCV}$-infected individuals, we purified $\mathrm{CD}^{+} \mathrm{CD} 45 \mathrm{RO}^{-}$naive and $\mathrm{CD}^{+}{ }^{+} \mathrm{CD} 45 \mathrm{RA}^{-}$memory $\mathrm{T}$ cells from $\mathrm{HCV}^{+/-}$subjects and cultured the cells without stimulation for $0,2,4$ days, followed by measuring the Annexin $\mathrm{V}$ (Av)/7-Aminoactinomycin D (7AAD) expressions. As shown in 


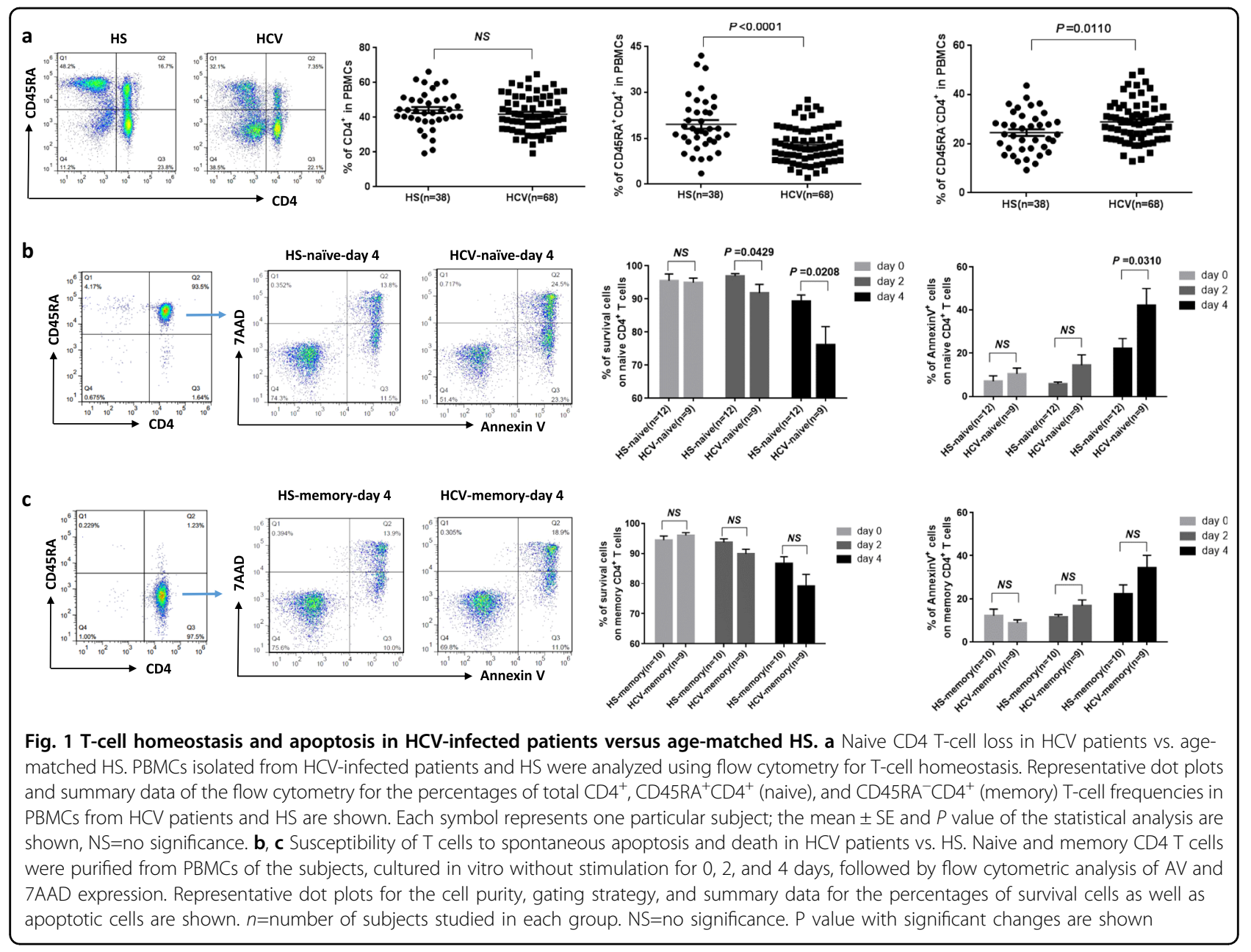

Fig. 1b, c, although healthy $\mathrm{T}$ cells showed signs of apoptosis/death accrual, an increased T-cell apoptosis and decreased cell survival rate were observed in HCVinfected patients, especially in the naive CD4 T-cell pools. By day 4 in culture without stimulation, $~ 90 \%$ of healthy naive $\mathrm{T}$ cells were alive, whereas only $75 \%$ of the $\mathrm{HCV}$ naive $\mathrm{T}$ cells still remained survival. Notably, increased apoptotic propensity (Av expression) was inversely associated with cell survival rate, with $\mathrm{HCV}$ naive $\mathrm{T}$ cells more prone to spontaneous apoptosis compared with the HS. By day 4 in culture without stimulation, HCV naive T cells exhibited significant apoptosis compared with HS ( 40\% vs. $\sim 20 \%, P<0.05)$, which negatively correlated with the cell numbers present in the peripheral blood from the same individuals (data not shown). These results suggest that apoptotic susceptibility of $\mathrm{T}$ cells from $\mathrm{HCV}$-infected subjects may be one mechanism contributing to the disproportionate $\mathrm{T}$-cell loss, whereas lack of thymic influx in aging adults and increases of naive $\mathrm{T}$-cell differentiation into antigenspecific effector and memory $\mathrm{T}$ cells during persistent viral infection may be other mechanisms for the different outcomes of the two T-cell subsets.

\section{DNA damage in naive CD4 T cells from HCV-infected patients}

Why naive CD4 T cells are susceptible to apoptosis and loss in virally infected individuals is unclear. Unlike activated or memory $\mathrm{T}$ cells, resting naive $\mathrm{T}$ cells typically do not express Fas surface receptor (Supplementary Figure S1A). In addition, blocking the extrinsic death pathways by disrupting Fas-Fas ligand, TNF $\alpha$-TNF receptor, and TRAL-TRAIL receptor interactions in CD4 T cells did not affect cell apoptosis or death rates (data not shown), indicating they are resistant to the exogenous apoptotic pathway-mediated cell death, but sensitive to endogenous oxidative stress, particularly ROS-mediated genotoxicity ${ }^{20}$. To assess endogenous DNA damage as a possible cause of impaired $\mathrm{T}$-cell survival, $\mathrm{CD} 4{ }^{+} \mathrm{CD} 45 \mathrm{RO}^{-}$naive and $\mathrm{CD} 4{ }^{+} \mathrm{CD} 45 \mathrm{RA}^{-}$memory $T$ cells were isolated from $\mathrm{HCV}$-infected patients and agematched HS, cultured in vitro without stimulation for 


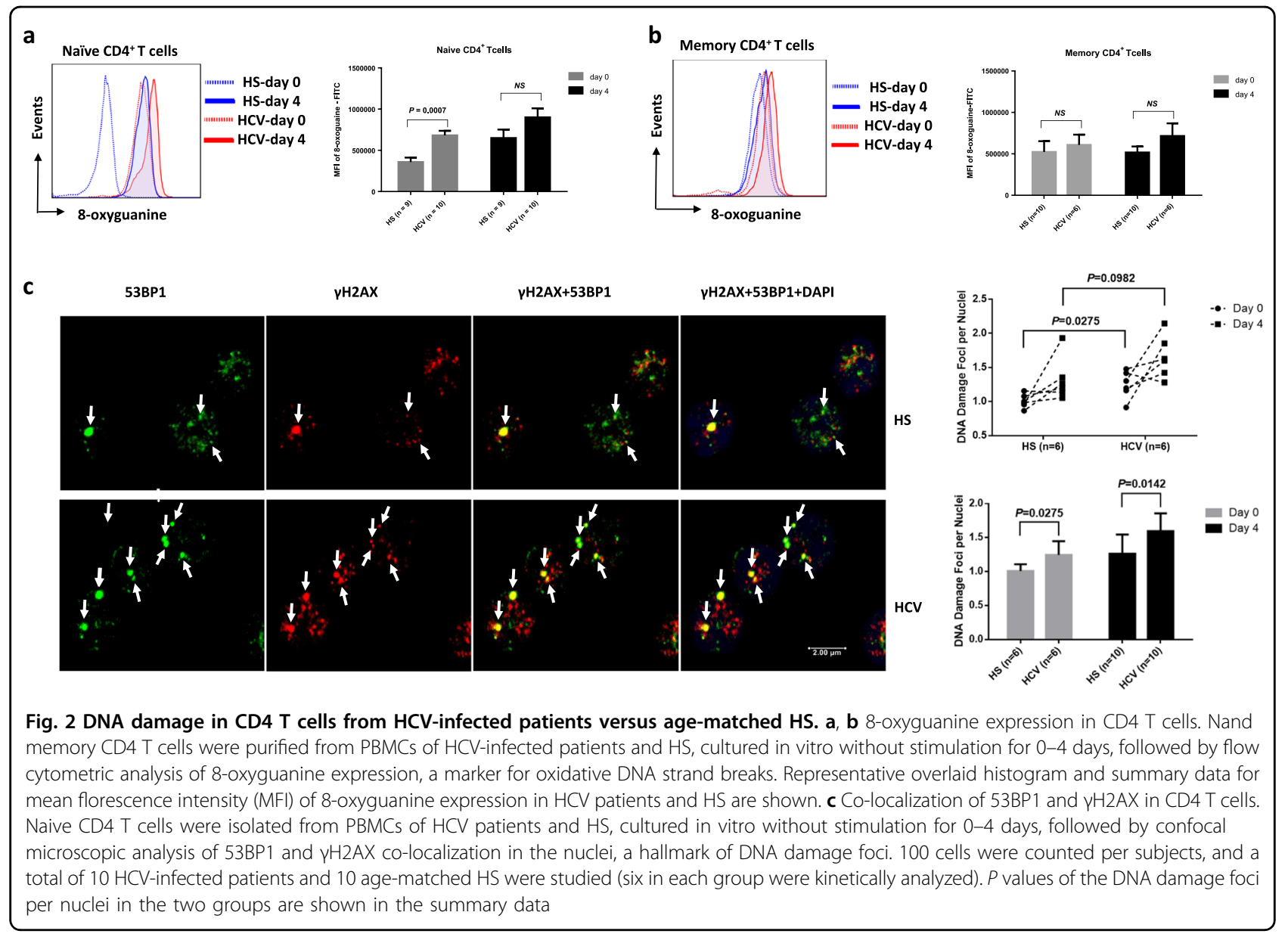

0-4 days, followed by DNA integrity analysis by measuring the expression of 8-oxogunine (8-oxoG), a marker for DNA-DSBs that are caused by excessive oxidative stress ${ }^{21}$. As shown in Fig. 2a, b (representative overlaid histogram and summary data of flow cytometry), resting naive CD4 $\mathrm{T}$ cells derived from $\mathrm{HCV}$-infected patients had significantly higher expression of 8-oxoG DNA bases compared to HS, indicating an accumulation of DNA lesions during chronic viral infection. After culturing cells without mitogenic or antigenic stimulation, both $\mathrm{HCV}$ and HS $\mathrm{T}$ cells showed increases in the expression of 8-oxoG. However, the extent of this increase in HCV naive T cells was less than that in HS. This could be attributed to (i) the relatively high baseline 8-oxoG level in HCV naive T cells at day 0 , and (ii) the test saturation of 8-oxoG load in $\mathrm{T}$ cells under these culture conditions with oxidative DNA stress, which could limit the 8-oxyG differences between $\mathrm{HCV}$ and $\mathrm{HS} \mathrm{T}$ cells at day 4 in culture. In contrast, memory $\mathrm{T}$ cells from $\mathrm{HCV}$ and $\mathrm{HS}$ exhibited an overload of 8-oxoG at baseline. After culturing cells without stimulation, 8-oxoG levels only slightly increased, although $\mathrm{HCV}$ memory $\mathrm{T}$ cells exhibited marginally higher DNA lesions than HS at baseline (day 0 ) and 4 days in culture. These data indicate that naive $\mathrm{T}$ cells from $\mathrm{HCV}$ patients exhibit oxidative DNA-DSBs that remain unrepaired during viral infection.

Following genotoxic insult, histone variant $\mathrm{H} 2 \mathrm{AX}$ is recruited to the site of DNA-DSBs and becomes phosphorylated at its C-terminal Ser-139 residue to form the $\gamma \mathrm{H} 2 \mathrm{AX}$ complex, which subsequently acts as a docking site for other mediators or adaptor proteins, such as 53BP1, to form microscopically visible nuclear focus (DNA damage foci)-a hallmark of DNA damage response $(\mathrm{DDR})^{27,28}$. To confirm that DNA damage occurs in $\mathrm{T}$ cells during $\mathrm{HCV}$ infection, we purified naive and memory $\mathrm{CD} 4 \mathrm{~T}$ cells from $\mathrm{HCV}^{+/-}$subjects and compared DNA damage foci by examining the colocalization of $\gamma \mathrm{H} 2 \mathrm{AX} / 53 \mathrm{BP} 1$ per nuclei using confocal microscopy. As shown in Fig. 2c (representative imaging and summary data of confocal microscopy), the number of DNA damage foci was significantly higher in the naive CD4 T cells freshly isolated from HCV patients compared with the HS. We also observed an increase in DNA damage foci in memory CD4 $\mathrm{T}$ cells derived from $\mathrm{HCV}$ patients versus HS (Supplementary Figure S1B). When the cells were cultured without stimulation for 4 days, the 


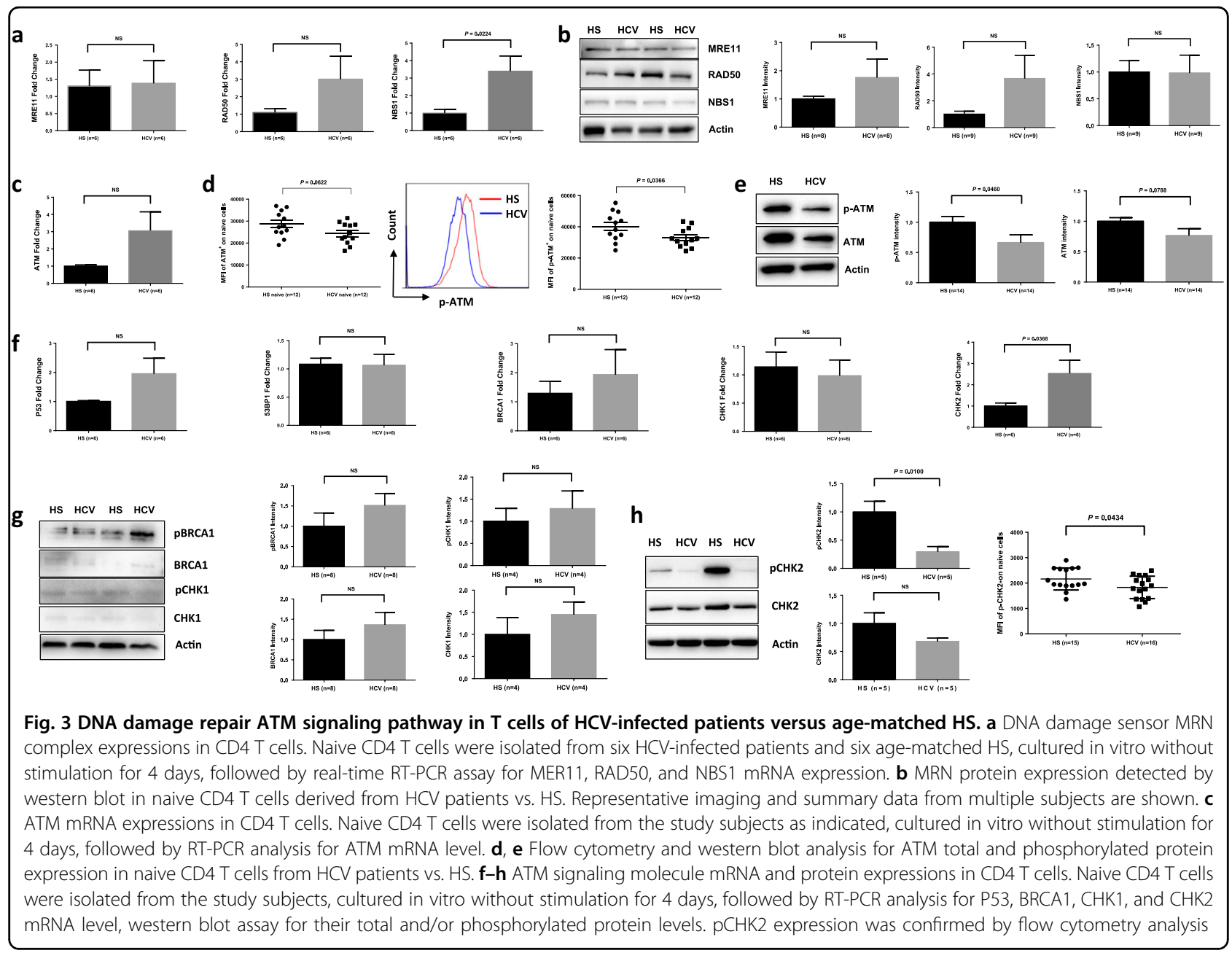

DNA damage foci increased, and were significantly higher in the naive $\mathrm{CD} 4 \mathrm{~T}$ cells from $\mathrm{HCV}$ patients compared with the HS. These results, in conjunction with the changes in T-cell frequency and apoptotic death, suggest that unrepaired DNA damage is associated with T-cell apoptosis and loss in individuals with chronic $\mathrm{HCV}$ infection, emphasizing the role of DNA damage repair to secure T-cell survival.

\section{DNA damage sensing and repairing machineries in naive CD4 T cells from HCV-infected individuals}

Accumulation of DNA-DSBs in CD4 T cells from HCV patients indicates that the DNA damage sensing and repairing machinery is disrupted. Essential components of this machinery include DNA damage sensors, such as MRN complexes (MRE11, RAD50, and NBS1), which recruit and mediate the DNA repair kinase ATM that can phosphorylate several downstream checkpoint proteins (such as p53, BRCA1, Chk1, and Chk2) ${ }^{22-24}$. To investigate the cellular machineries that contribute to the DNA damage repair, we examined mRNA transcripts and protein expressions of these DDR molecules in naive CD4 $\mathrm{T}$ cells from $\mathrm{HCV}$-infected patients and HS using realtime RT-PCR and western blotting or flow cytometry. As shown in Fig. 3a, the mRNA levels of MRN complexes showed no difference or higher levels of MER11, RAD50, and NBS1. In parallel, the protein levels of these DNA damage sensors in naive $\mathrm{CD} 4 \mathrm{~T}$ cells were also unchanged or slightly higher in HCV compared with HS (Fig. 3b). Intriguingly, although the mRNA level of ATM was higher (Fig. 3c), its protein level was lower; particularly, ATM phosphorylation (pATM) was significantly lower in $\mathrm{HCV}$ naive $\mathrm{CD} 4 \mathrm{~T}$ cells in the 4-day culture compared to the HS, as measured by flow cytometry (Fig. 3d) and western blot (Fig. 3e). Similarly, the mRNA expressions of ATM signaling molecules, P53, 53BP1, BRCA1, CHK1, and CHK2 remained unchanged or even higher in naive CD4 $\mathrm{T}$ cells from $\mathrm{HCV}$ patients when compared to the HS (Fig. 3f). However, pp53 protein was undetectable in resting naive $\mathrm{CD} 4 \mathrm{~T}$ cells without stimulation, whereas BRCA1 and CHK1 total and phosphorylated proteins remained unchanged (Fig. 3g); CHK2 protein, especially 


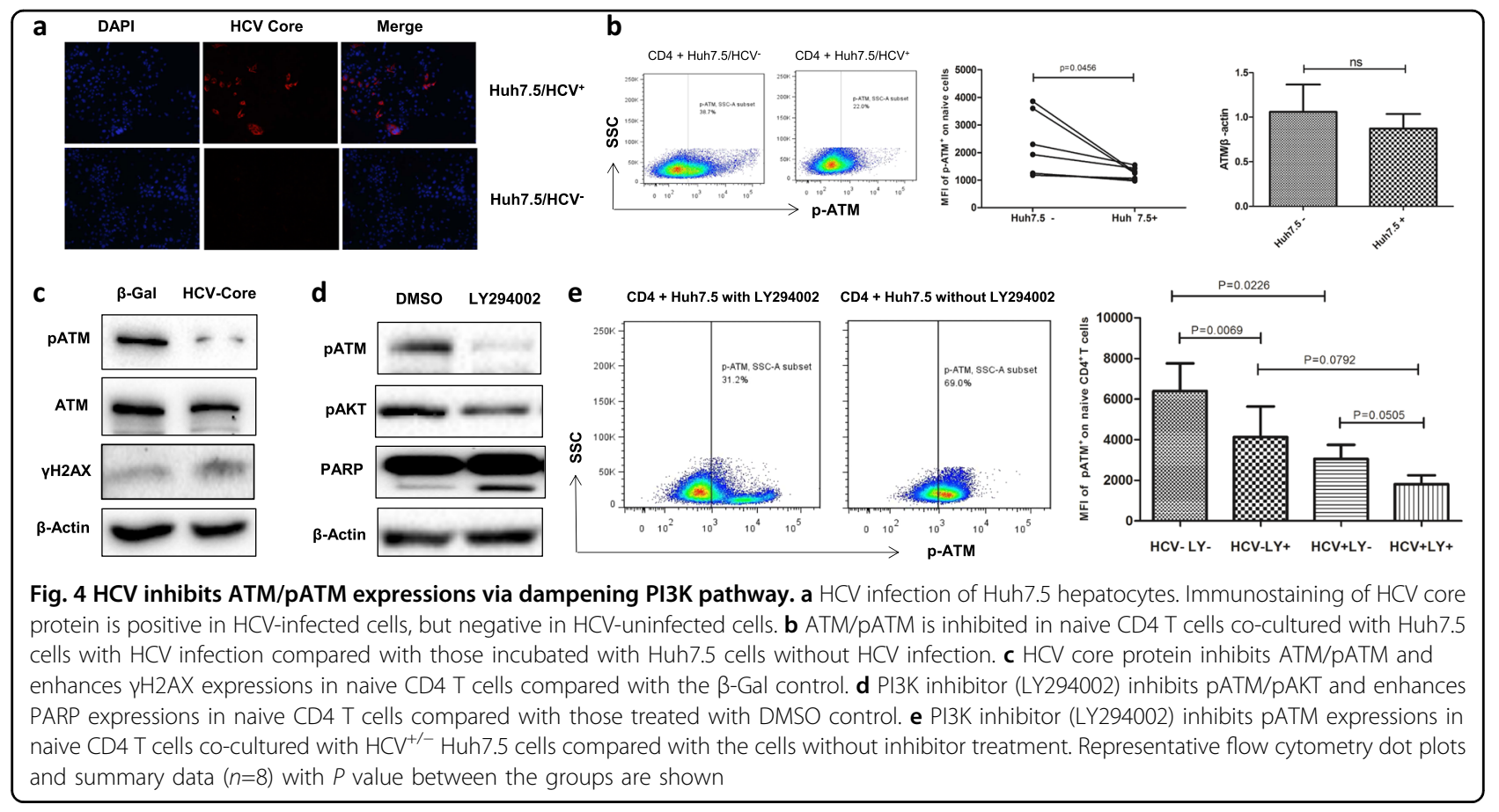

pCHK2, was significantly suppressed in $\mathrm{HCV} \mathrm{T}$ cells compared to the HS, as demonstrated by western blot and flow cytometry (Fig. 3h). These results suggest that the DNA damage sensing machinery may be intact, but the DNA repair (ATM/CHK2) pathway is inhibited, at the post-transcriptional levels, especially the phosphorylation process essential for its activation and function.

\section{Role of HCV in dampening ATM activation and its effects on DNA damage and cell apoptosis}

As chronically $\mathrm{HCV}$-infected patients often have other co-morbidities that may cause immune dysregulation, we examined the specific role of HCV in triggering DDR and promoting cellular senescence or apoptosis. We incubated naive CD4 T cells with Huh7.5 cells with or without HCV infection, followed by measuring ATM activation. As shown in Fig. 4a (immunofluorescence staining of Huh7.5 cells with or without infection by HCV JFH-1 strain), hepatocytes transfected with HCV RNA at $48 \mathrm{~h}$ showed positive expression of $\mathrm{HCV}$ core protein, whereas cells with mock transfection exhibited negative staining. Moreover, we detected HCV RNA in the supernatant of $\mathrm{HCV}$-transfected cells (at $24 \mathrm{~h}$ as well as $48 \mathrm{~h}$ ), but not mock-transfected cells (data not shown). Importantly, similar to the observations in $\mathrm{HCV}$ patients (Fig. 3b), whereas the total ATM protein expression was not significantly decreased, the phosphorylation of ATM was markedly inhibited in the naive CD4 $\mathrm{T}$ cells that were incubated with $\mathrm{HCV}^{+}$Huh7.5 cells compared with cells co-cultured with $\mathrm{HCV}^{-}$Huh7.5 hepatocytes (Fig. 4b). In addition, $\mathrm{T}$ cells exposed to HCV-expressing hepatocytes were more apoptotic, as demonstrated by a significant increase $(P=0.0357)$ in Av/7AAD expression in CD4 $\mathrm{T}$ cells exposed to $\mathrm{HCV}$ compared with the negative control (data not shown).

We have previously shown that primary $\mathrm{T}$ cells treated with $\mathrm{HCV}$ core protein exhibited a senescent state, as evidenced by a higher level of the aging marker $\beta$ Galactosidase expression and shortened telomeres ${ }^{5}$. To further investigate whether $\mathrm{HCV}$ core-treated T cells have impairment in the DNA damage repair enzyme ATM, we exposed healthy naive CD4 T cells to HCV core protein, which is secreted by virally infected hepatocytes and circulates in the peripheral blood of HCV-infected patients and can dampen $\mathrm{T}$ cells through its interaction with the globulin head of C1q receptor expressed on the surface of $\mathrm{T}$ cells, thus delivering inhibitory signaling ${ }^{29,30}$. As shown in Fig. 4c, compared to the $\beta$-gal control, treatment with $\mathrm{HCV}$ core protein for 5 days significantly inhibited the phosphorylation of ATM, but not total ATM protein expression, in naive CD4 $\mathrm{T}$ cells. In addition, HCV coretreated $\mathrm{T}$ cells exhibited an increased level of $\gamma \mathrm{H} 2 \mathrm{AX}$ (a marker of DNA damage), suggesting that insufficient pATM is associated with an increased DNA damage in HCV core-treated T cells.

ATM belongs to the PI3K family, and we have previously shown that $\mathrm{HCV}$ can induce $\mathrm{T}$-cell senescence by inhibiting the AKT/PI3K pathway ${ }^{3}$. To further explore the mechanisms that might be involved in inhibiting ATM activation, we treated naive CD4 T cells with LY294002 (a potent PI3K-specific inhibitor) in the presence or absence of HCV core protein. As shown in Fig. 4d, compared with 


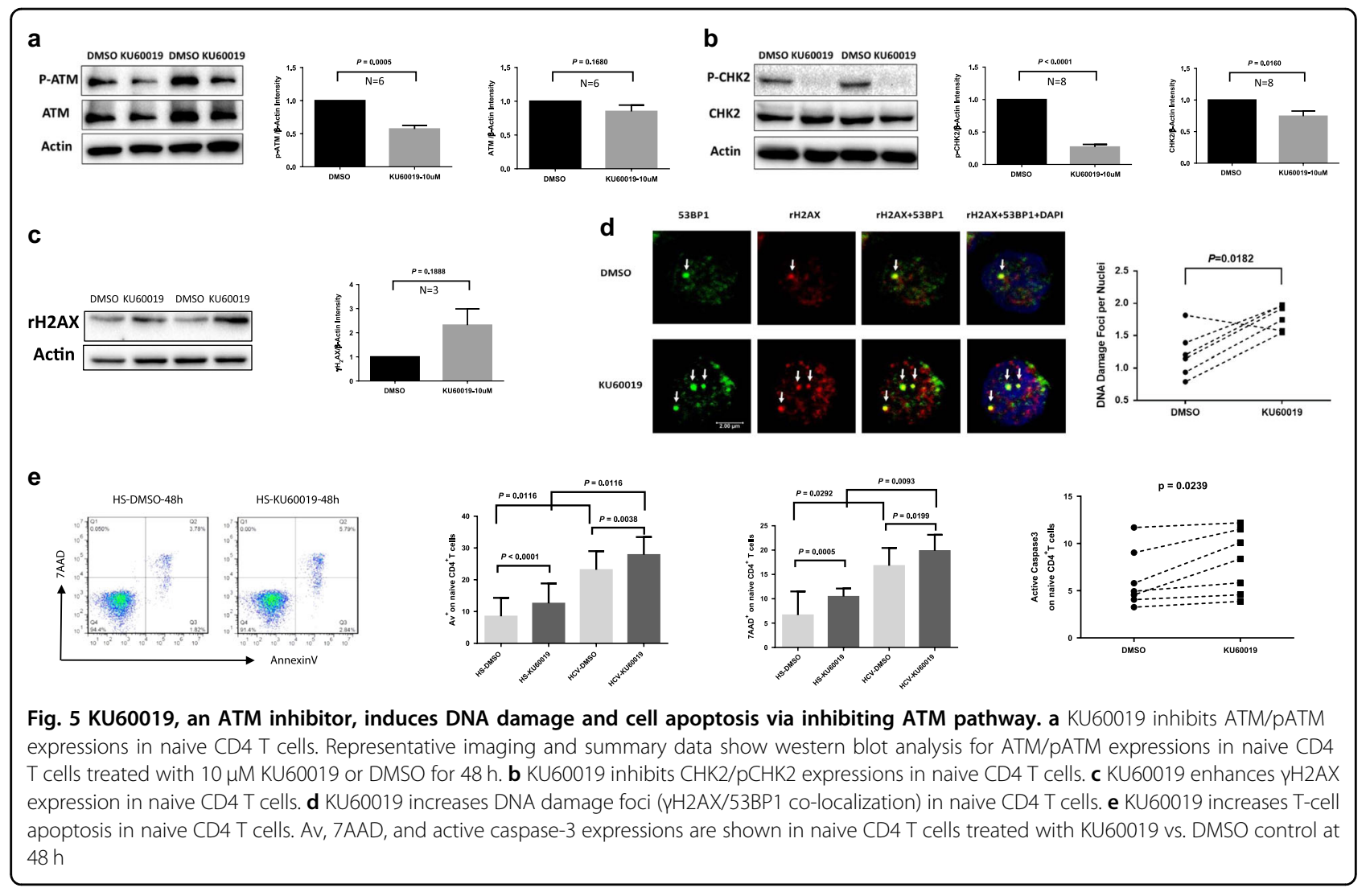

the DMSO-treated control, T cells treated with $20 \mu \mathrm{M}$ LY294002 exhibited remarkable inhibition of pATM, along with decreases in pAKT. Moreover, the cleaved form of Poly (ADP-ribose) polymerase (PARP), an enzyme that catalyzes the transfer of ADP-ribose onto target proteins and plays an important role in DNA repair and cell survival, was significantly increased in $\mathrm{T}$ cells treated with the PI3K inhibitor. In addition, we assessed the effect of LY294002 on ATM inhibition in CD4 T cells cocultured with $\mathrm{HCV}^{+/-}$Huh7.5 cells. As shown in Fig. 4e, pATM expression in CD4 $\mathrm{T}$ cells in the presence of Huh7.5 hepatocytes without $\mathrm{HCV}$ infection was significantly inhibited by the PI3K inhibitor. pATM expression was further inhibited in naive CD4 T cells incubated with $\mathrm{HCV}^{+}$Huh7.5 cells, especially in the presence of PI3K inhibitor. These results suggest that HCV (core protein) can induce T-cell DNA damage that is associated with impaired ATM via inhibition of the PI3K.

\section{Inhibition of ATM phosphorylation in naive CD4 T-cell leads to DNA damage and apoptosis}

The ATM signaling pathway is pivotal to the maintenance of genome integrity and cell survival ${ }^{26}$. To test the functionality of this DNA repair machinery in T-cell survival, freshly isolated healthy naive $\left(\mathrm{CD} 4^{+} \mathrm{CD} 45 \mathrm{RO}^{-}\right)$
$\mathrm{T}$ cells were treated with a specific ATM inhibitor (KU60019, $10 \mu \mathrm{M}$ ) for $48 \mathrm{~h}$, followed by measuring DNA damage and cell apoptosis or death. As shown in Fig. 5a, naive T cells exposed to KU60019 showed an inhibition in ATM, in particular pATM, compared with the DMSO control. In addition, the phosphorylation of CHK2 protein, a downstream effector of ATM signaling pathway, was significantly inhibited by the treatment (Fig. 5b). Importantly, $\mathrm{T}$ cells exposed to the ATM inhibitor exhibited an elevated $\gamma \mathrm{H} 2 \mathrm{AX}$ expression, suggesting an increase in DNA damage (Fig. 5c). In addition, T cells treated with the ATM inhibitor exhibited an increase in DNA damage foci $(\gamma \mathrm{H} 2 \mathrm{AX} / 53 \mathrm{BP} 1$ co-localization) compared with the control (Fig. 5d). Moreover, ATM inhibition in naive $\mathrm{CD} 4 \mathrm{~T}$ cells resulted in considerately increased T-cell apoptosis and death, as demonstrated by an increase in Av and 7ADD expression, as well as activated caspase- 3 following the treatment (Fig. 5e). In essence, an insufficiency of ATM leads to greater DNA damage and cell apoptotic death, which may necessitate compensatory homeostatic proliferation and lead to telomere loss and premature senescence, particularly in the naive T-cell pool, a mechanism that can potentially contribute to the naive $\mathrm{T}$-cell loss and poor immune (vaccine) responses in chronic HCV infection. 


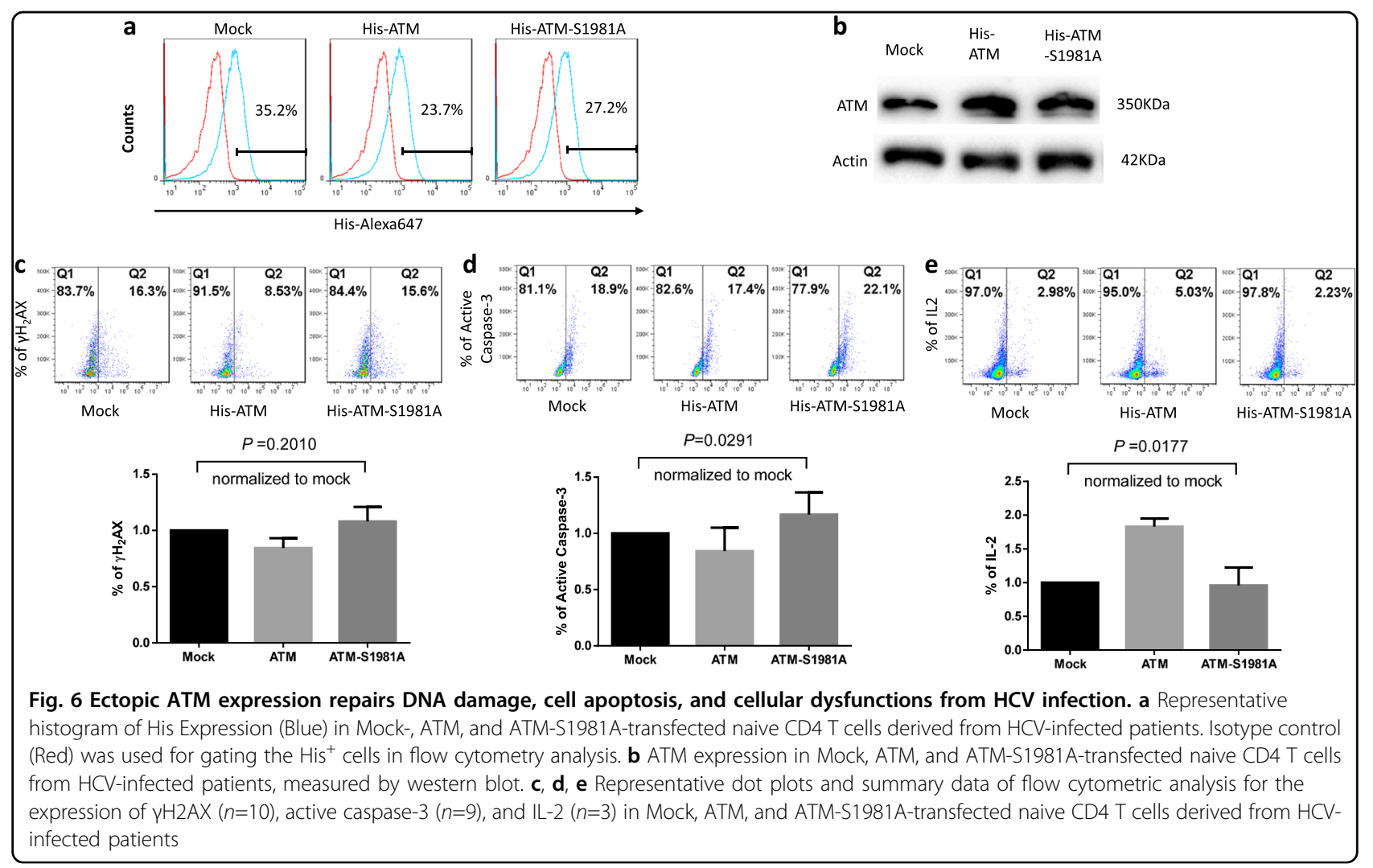

\section{Reconstitution of ATM in HCV CD4 T cells repairs DNA damage, survival defect, and cellular functions}

Given the critical role of ATM in repairing DNA-DSBs, we hypothesized that reconstitution of ATM could protect $\mathrm{HCV}$-derived $\mathrm{T}$ cells from DNA damage and restore the signaling network required for repairing DNA breaks. To test this, we transfected CD4 $\mathrm{T}$ cells derived from HCV-infected individuals with Flag-His-ATM constructs or controls, including an empty vector without ATM insert (Mock), and an ATM mutant (ATM-S1981A) in which the serine $(S)$ phosphorylation site at residue number 1981 was substituted by alanine (A), using the Lonza transfection system. Despite high transfection efficiency (70\%) with GFP transfection by this system, fluorescence-activated cell sorting analysis revealed intracellular His-ATM expression in only $20-40 \%$ of the $\mathrm{T}$ cells transfected with Flag-His-ATM or control constructs (Fig. 6a). Western blotting confirmed an increase in ATM expression in the wild-type, as well as mutant ATM-S1981A-transfected T cells (Fig. 6b). Although ectopic overexpression of ATM had broad biological consequences, we focused our investigation on the DNA repair, cell survival, and cell function, by assessing $\gamma \mathrm{H} 2 \mathrm{AX}$, caspase-3, and IL-2 expression levels as readout. As shown in Fig. 6c, compared to mock transfection, ATM reconstitution reduced $\gamma \mathrm{H} 2 \mathrm{AX}$ expression after 48 $\mathrm{h}$, whereas transfection of the non-phosphorylated form with an ATM-S1981A mutant was unable to restore the level of DNA repair, indicating the importance of ATM phosphorylation at serine 1981 in protecting cells from excessive DNA breaks. In parallel, transfection of wildtype ATM significantly reduced T-cell apoptosis, whereas mock- or ATM-S1981A-transfected cells exhibited relatively higher levels of active caspase-3 expression (Fig. 6d), suggesting that ectopic ATM expression exerts immediate effects in determining T-cell fate by securing cell survival. Most importantly, implementing ATM significantly improved T-cell function, as shown by the increase in IL2 expression in ATM-transfected cells, whereas ATMS1981A transfection could not induce such an effect (Fig. 6e). Taken together, these results suggest that restoring an adequate ATM level in naive CD4 T cells from chronic HCV infection is sufficient to ameliorate DNA damage, survival defects, and cell dysfunctions.

\section{Discussion}

We and others have previously shown that $\mathrm{T}$ cells derived from patients with chronic viral infections prematurely reach senescence, characterized by the shortening of telomeres and expression of aging markers ${ }^{2-6}$. In this study, we further demonstrate that homeostatic remodeling of the $\mathrm{T}$-cell repertoire during $\mathrm{HCV}$ infection 
primarily affects the naive T-cell compartment, characterized by an accumulation of DNA damage owing to insufficient activation of the DNA repair ATM enzyme, which leads to naive $\mathrm{T}$-cell apoptosis and loss. Indeed, phosphorylation of ATM in T cells exposed to HCV (core protein) is inhibited through dampening the PI3K pathway, resulting in an increase in DNA damage and cell apoptosis. Moreover, pharmacological inhibition of ATM phosphorylation leads to more DNA damage and apoptosis in naive $\mathrm{T}$ cells. Most importantly, reconstitution of ATM repairs the DNA damage, cell apoptosis, and functional defects in naive $\mathrm{CD} 4 \mathrm{~T}$ cells derived from $\mathrm{HCV}$-infected patients. Based on these novel findings, we propose a model (depicted in Fig. 7) where HCV-induced ATM deficiency leads to accumulation of DNA damage and cell apoptosis. The excessive T-cell loss necessitates high homeostatic proliferation and imposes replicative stress on unprimed naive $\mathrm{T}$ cells; this represents a novel molecular mechanism underlying $\mathrm{T}$-cell senescence in the setting of chronic viral infection. Importantly, ectopic overexpression of ATM is necessary and sufficient to repair the DNA damage, survival defect, and cell dysfunctions in HCV-derived T cells, thus providing a new strategy to improve immunotherapy and vaccine responses against human viral diseases.

We and others have observed poor vaccine responses in the setting of chronic viral (HCV, HIV) infections ${ }^{2,3,15-19}$, but the underlying mechanisms for vaccine failure in virally infected individuals remain unclear. Data presented in this study indicate that naive helper $\mathrm{T}$ cells in chronically HCV-infected patients have abnormalities that jeopardize their ability to mount effective immune (vaccine) responses. Specifically, we demonstrated that naive CD4 $\mathrm{T}$ cells have accumulation of damaged DNA and fail to repair their DNA-DSBs owing to deficiency of the ATM pathway. Accumulated DNA damage renders HCVderived $\mathrm{T}$ cells prone to apoptotic death, imposing replicative stress and premature aging on naive $\mathrm{T}$ cells. These findings are important because naive $\mathrm{T}$ cells represent the reserve pool of the immune system, and their survival critically determines the cellular yield of homeostatic proliferation, a process that generates new $\mathrm{T}$ cells in response to neo-antigens, including vaccines.

Insufficient activation of ATM would be expected to affect both unprimed and primed $\mathrm{T}$ cells. Indeed, we observed unrepaired DNA damage and cell apoptosis in both naive and memory $\mathrm{T}$-cell populations. However, ongoing antigenic stimulation during chronic viral infection could drive naive T-cell differentiation and turnover of antigen-reactive $\mathrm{T}$ cells. In this regard, memory $\mathrm{T}$ cells would expand and compromise the size and survival of naive $\mathrm{T}$ cells. Eventually, the entire T-cell pool would be comprised by antigen-reactive $\mathrm{T}$ cells at the expense of naive $\mathrm{T}$ cells. In the setting of chronic viral infection,

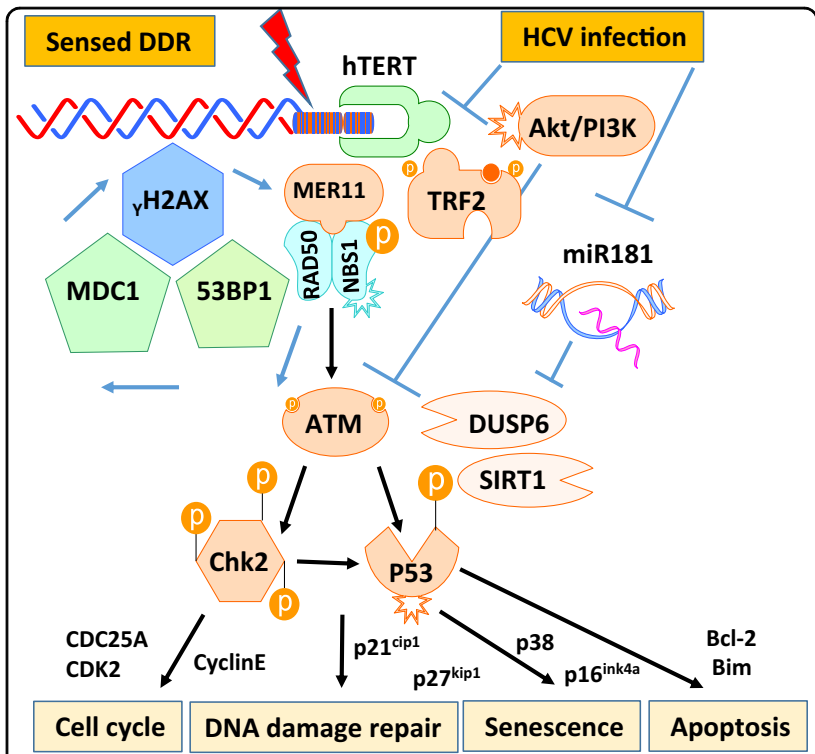

Fig. 7 A novel model of HCV-induced ATM deficiency in T-cell cycle arrest, DNA damage repair, cell senescence, and apoptosis. $\mathrm{HCV}$ infection triggers a DNA damage response (DDR) in the early phase via activation of MRN-ATM-CHK2 and P53 signaling pathways in naive CD4 T cells, prompting cell cycle arrest and allowing for DNA damage repair; or, if the infection is overwhelming and causes unrepairable DNA damage, the cell will commit suicide and initiates programmed cell death (apoptosis). Persistent antigenic and inflammatory stimulation, however, drives ATM exhaustion and insufficiency, leading to impaired DNA damage repair and accumulation of DNA double strain breaks (DSBs), which result in constant cell apoptosis and naive T-cell loss. Excessive T-cell loss necessitates high homeostatic proliferation and imposes replicative stress on unprimed naive T cells, emerging as a novel molecular mechanism underlying T-cell senescence in the setting of chronic viral infection. Importantly, ectopic overexpression of ATM is necessary and sufficient to repair the DNA damage, survival deficit, and cellular dysfunction in HCV-derived T cells, providing a new strategy to improve immunotherapy and vaccine responses against human viral diseases

however, memory $\mathrm{T}$ cells could be functionally biased as a result of chronic antigenic stimulation; as such, we focused our studies on the T-cell population that has yet to be recruited for immune responses. With the decrease in newly generated naive thymic $\mathrm{T}$ cells in adults, chronic infection or inflammation might force the immune system to restore equilibrium by replicating the available or existing naive $\mathrm{T}$ cells, thereby driving telomere shortening and senescence in naive $\mathrm{T}$-cell populations. Thus, the ability to generate immune response to new antigens, such as HBV vaccine, could be compromised.

ATM has a unique role in lymphocyte biology, as programmed DNA damage repair is part of the gene rearrangement necessary for formation of a highly diverse $\mathrm{T}$ cell receptor repertoire. Under non-stress conditions, ATM is inactive and exists in the form of a dimer (like other PI3Ks). It requires a signal for activation (usually a 
DNA damage signal), signaling through intermolecular autophosphorylation at ATM residue S1981 and resulting in the dimer dissociation into monomers ${ }^{31}$. In our study, a mutant of S1981A rendered ATM a dominant-negative protein, triggering more severe DNA damage $(\gamma \mathrm{H} 2 \mathrm{AX}$ expression), cell apoptotic death (Av/7AAD expression), and cellular dysfunction (IL-2 inhibition)—underscoring the importance of ATM phosphorylation for its biological functions. ATM is predominantly localized in the nucleus, and undergoes activation once the MRN complex senses and binds to DNA DSB ends, providing a platform for ATM recruitment and autophosphorylation ${ }^{32,33}$. Phosphorylation of S1981 also stabilizes ATM at the damaged DNA sites and recruits more downstream effector proteins to participate in the $\mathrm{DDR}^{34}$. Among the multiple substrates phosphorylated by ATM is the checkpoint kinase 2 (CHK2), which is phosphorylated at residue T62 following DSB formation and prevents cells from progressing from $\mathrm{G} 1$ to $\mathrm{S}$ phase or, alternatively, leads to cell apoptosis. The discovery of these DNA damage response proteins has shed light on the cellular machinery that contributes to DNA repair and cell homeostasis.

Recently, Li et al..$^{35}$ identified prematurely aged $\mathrm{T}$ cells with damaged telomeres in patients with rheumatoid arthritis, resulting from defective activity of the DNA break sensor MER11A. In patients with chronic HCV infection, however, we find that the DNA damage sensor MRN complex is intact in naive T cells. Rather, the DNA damage repair enzyme ATM is inhibited, at a posttranscriptional level, by HCV infection. Interestingly, Guo et al. ${ }^{36,37}$ reported that ATM activation in response to ROS was independent of the MRN complex. ROSmediated ATM signaling represses mTORC1 signaling and therefore cell growth and proliferation through activation of TSC2 (a negative regulator of MTOR) by liver kinase B1 (also known as STK11) and AMP-dependent protein kinases ${ }^{38}$. ATM engagement of the TSC2/ mTORC1 signaling pathway can also regulate autophagy $^{39}$, and differential localization of ATM is correlated with activation of distinct downstream signaling pathways ${ }^{40}$. We have previously reported that $\mathrm{T}$ cells treated with HCV core protein exhibit G1/S cell cycle arrest, which was associated with the dysregulation of cell cycle regulatory proteins CDKs/Cyclins and P27 ${ }^{\text {kip } 1}{ }^{41}$. Here, we demonstrate that concomitant with the insufficiency of ATM activation, the phosphorylation of CHK2 is defective in naive $\mathrm{T}$ cells from HCV-infected patients. Moreover, pharmacological inhibition of ATM in healthy $\mathrm{T}$ cells also leads to a CHK2 defect, accompanied by a marked increase in DNA damage and cell apoptosisresembling the biological effects characteristic of HCVderived naive $\mathrm{T}$ cells. These results establish that in human T cells, CHK2 is targeted by ATM, and that the overall defect of this pathway can be attributed to ATM insufficiency owing to chronic HCV infection.

A typical feature of $\mathrm{CD} 4 \mathrm{~T}$ cells in chronically $\mathrm{HCV}$ infected patients is the shortening of telomeres compared with age-matched healthy controls ${ }^{5,6}$. Several mechanisms may contribute to this age-associated loss of telomeres. Increased proliferative turnover can cause cell division-induced telomere shortening. In addition, telomeric DNA is highly susceptible to DNA damage, even more so than non-telomeric DNA. Plasmid-inserted human telomeres accumulate sevenfold higher strand breakage than control sequences ${ }^{42}$. Also, the frequency of single-strand breaks is several-fold higher in telomeres than in the bulk genome when cells are treated with alkylating agents or exposed to oxidative stress ${ }^{43}$. In line with these findings, we have recently found that the expression of the telomere shelterin TRF2 is significantly inhibited, at the protein level, in naive $\mathrm{CD} 4 \mathrm{~T}$ cells derived from $\mathrm{HCV}$-infected individuals, which renders the uncapped telomeres prone to DNA damage (unpublished observations). Thus, telomere loss in $\mathrm{HCV} \mathrm{T}$ cells is triggered by DDR and the inability of timely repair by the ATM signaling pathway. In addition, we have also discovered that KML001, a telomere-targeting drug, can induce telomeric DNA damage and T-cell apoptosis by impairing the ATM pathway (unpublished observations). Notably, ATM is widely expressed in human T cells at an extremely high level to ensure integrity of the genomic DNA in replicating lymphocytes. ATM activation represents the initiation of DDR, but its inhibition in persistently stimulated $\mathrm{T}$ cells indicates insufficiency of this DNA repair enzyme and cell exhaustion and senescence in the setting of chronic viral infection. This notion is supported by our observation in an in vitro stimulated $\mathrm{T}$ cell system that ATM phosphorylation is increased in the early phase of KML001-treated T cells $(3 \sim 6 \mathrm{~h})$ and decreased in persistently treated cells $(24 \sim 48 \mathrm{~h})$, along with increases in DNA damage, cell apoptosis, and functional impairment (unpublished observations).

In summary, accumulation of DNA damage and failure to repair the DNA-DSBs owing to deficiency of the ATMdependent DNA repair machinery during chronic viral infection may have broader implications through impairing diverse cellular functions. As interferon (IFN)mediated T-cell apoptotic death has been well-studied in persistent viral infections ${ }^{44-47}$, this virus-induced DNA damage-mediated T-cell loss represents a new mechanism of immune evasion. How HCV induces DNA-DSBs, and its relationship to the IFN-signaling pathway, are under further investigation. As counteracting ATM deficiency may restore $\mathrm{T}$-cell competency during viral infection and prevent premature immune aging, these studies may provide new strategies to improve immunotherapy and vaccine responses against human viral diseases. 


\section{Materials and Methods}

\section{Subjects}

The study protocol was approved by the institutional review board (IRB) of East Tennessee State University and James H. Quillen VA Medical Center (ETSU/VA IRB, Johnson City, TN, USA). The study subjects were composed of two populations: 148 chronically HCV-infected individuals and 72 age-matched HS. Written informed consent was obtained from all participants. HCV patients were virologically positive for HCV RNA, prior to the antiviral treatment. Healthy subjects, derived from Physicians Plasma Alliance, Gray, TN, USA were negative for $\mathrm{HBV}, \mathrm{HCV}$, and HIV infection.

\section{Cell isolation and culture}

PBMCs were isolated from whole blood by Ficoll (GE Heathcare, Piscataway, NJ, USA) density centrifugation. Naive and memory CD4 ${ }^{+} \mathrm{T}$ cells were isolated from PBMCs using the naive or Memory $\mathrm{CD}^{+}{ }^{+} \mathrm{T}$ Cell Isolation Kit and a MidiMACS Separator (Miltenyi Biotec Inc., Auburn, CA). The isolated T cells were cultured in RPMI 1640 medium containing 10\% FBS (Atlanta Biologicals, Flowery Branch, GA, USA), $100 \mathrm{IU} / \mathrm{ml}$ penicillin and 2 mM L-glutamine (Thermo Scientific, Logan, UT, USA) without mitogenic stimulation for 4 days at $37{ }^{\circ} \mathrm{C}$ and $5 \%$ $\mathrm{CO} 2$ atmosphere. Cells were collected at day 0 , day 2 , or day 4 for detection of cell apoptosis and DNA damage. To test the role of pATM in repairing DNA damage and apoptosis, $10 \mu \mathrm{M}$ pATM inhibitor (KU60019, Abcam, Cambridge, MA) or dimethyl sulphoxide were added to the cultures for $48 \mathrm{~h}$, followed by apoptosis and DNA damage analysis. To consolidate the role of $\mathrm{HCV}$ in inhibiting ATM activation, purified naive CD4 T cells were co-cultured with Huh7.5 cells with or without HCV infection, or $1 \mu \mathrm{g} / \mathrm{ml}$ recombinant $\mathrm{HCV}$ core protein (Virogen, watertown, MA, USA) or control protein $\beta$ galactosidase (Virogen), in the presence or absence of 20 $\mu \mathrm{M}$ PI3K inhibitor (LY294002, Sigma) for 4 days, followed by flow cytometry or Western blot analysis for ATM/ pATM expression, DNA damage, and cell apoptosis.

\section{Flow cytometry}

For phenotypic analysis of naive CD4 T cells, PBMCs were stained with CD4-APC, CD45RA-FITC (BioLegend, San Diego, CA, USA) antibodies, or isotype controls. To quantify cell apoptosis, naive or memory cells were purified, cultured, and collected at indicated days and stained with Av and 7AAD using BD Pharmingen PE Av Apoptosis Detection Kit I (BD Biosciences, San Jose, CA, USA). For intracellular staining, the cells were fixed and permeabilized with Foxp3 Transcription Factor Staining Buffer Set (eBioscience, San Diego, CA, USA), and stained with pATM (Ser1981)-PE antibody(BioLegend), ATM antibody (Abcam), and anti-Rabbit-IgG-Alexa Fluor 488
(Santa Cruz Biotechnology, Dallas, TX, USA), pCHK2 (Thr68)-PE antibody (eBioscience), 8-oxoguaine-FITC probe (OxyDNA Assay Kit, EMD Millipore, Billerica, MA). The stained cells were analyzed on AccuriTM C6 flow cytometer (BD, Franklin Lakes, NJ), and data were analyzed by FlowJo software (Tree Star, Inc., Ashland, OR). Isotype control antibodies (eBioscience) and fluorescence minus one controls were used to determine the background levels of staining and adjust multicolor compensation as gating strategy.

\section{RNA isolation and real-time RT-PCR}

Total RNA was extracted from $1.0 \times 10^{6}$ cells with PureLink RNA Mini Kit (Invitrogen, Carlsbad, CA), and cDNA was synthesized by using High Capacity cDNA Reverse Transcription Kit (Applied Bio systems, Foster city, CA) per manufacturer's instruction. Quantitative PCR were completed in triplicates following the conditions $95^{\circ} \mathrm{C}, 10 \mathrm{~min}$ and then $95^{\circ} \mathrm{C}, 15 \mathrm{~s} ; 60^{\circ} \mathrm{C}, 60 \mathrm{~s}$ with 40 cycles. Gene expression was normalized to $18 \mathrm{~S}$ ribosomal RNA and expressed as fold changes using the $2^{-\Delta \Delta \text { ct }}$ method. Primer sequences were shown in Table 1.

\section{Western blotting}

Naive CD4 T cells purified from HCV-infected individuals and HS were lysed on ice in RIPA lysis buffer (Boston BioProducts Inc, Ashland, MA) in the presence of protease inhibitors (Thermo Scientific, Rockford, IL). The protein concentrations were measured by Pierce BCA protein assay kit (Thermo Scientific). Proteins were separated by SDS-PAGE, transferred to polyvinylidene difluoride membranes, which were blocked with $5 \%$ nonfat milk, $0.5 \%$ Tween-20 in Tris buffered saline, and incubated with the pATM (Ser1981) (D6H9), pBRCA1, pCHK1, and pCHK2 (Thr68) (C13C1) antibodies and $\beta$ Actin (8H10D10) antibodies (Cell Signaling, Danvers, MA). Appropriate horseradish peroxide-conjugated secondary antibodies (Cell Signaling) was then used and proteins were detected using Amersham ECL Prime Western Blotting Detection Reagent (GE Healthcare BioSciences, Pittsburgh, PA). Membranes were stripped and re-probed with MER11, RAD50, NBS1, BRCA1, ATM (D2E2), $\gamma \mathrm{H} 2 \mathrm{AX}$, PARP, CHK1, and CHK2 (D9C6) antibodies (Cell Signaling). Protein bands were captured and quantitatively analyzed by Chemi DocTM MP Imaging System (Bio-Rad System).

\section{Confocal microscopy}

Naive $\mathrm{CD}^{+} \mathrm{T}$ cells were isolated and cultured as described above. Immunofluorescence staining was performed according to the reported $\operatorname{method}^{39}$. In brief, the cells were fixed in $2 \%$ paraformaldehyde for 20 min, permeabilized with $0.3 \%$ Triton X-100 in PBS for $10 \mathrm{~min}$, blocked with $5 \%$ BSA in PBS for $1 \mathrm{~h}$, 
Table 1 Primer sequences

\begin{tabular}{ll}
\hline $\begin{array}{l}\text { Name of the } \\
\text { amplified genes }\end{array}$ & Primer sequences \\
\hline ATM & F: 5'-TGGATCCAGCTATTTGGTTGA-3' \\
& R: 5'-GATGAAGAAGATAACAACCAATGTATGAACC-3' \\
p53 & F: 5'-TCAACAAGATGTTTGCCAACTG-3' \\
& R: 5'-GTAGATGTTCGTCAGTGTCGTGTA-3' \\
MRE11 & F: 5'-CTTGTACGACTGCGAGTGGA-3' \\
NBS1 & R: 5'-GTCTTCTCCCTACCCACTT-3' \\
& F: 5'-TTGGTTGCATGCTCTTCTTG-3' \\
RAD50 & R: 5'-CAACTCAGGTTCTCGTCGG-3' \\
& F: 5'-CTTGGATATGCGAGGACGAT-3' \\
BRCA1 & R: 5'-CGCATTGAAGGTCGAAGACC-3' \\
& F: 5'-GGCTATCCTCTCAGAGTGACA-3' \\
CHEK1 & R: 5'-AGGTCTTGTTTCGTGTAGTC-3' \\
& F: 5'-GGTGAATATAGTGCTGCTATGTTGACA-3' \\
& R: 5'-CACAGTGAAGGGACAAATAGGT-3' \\
CHEK2 & F: 5'-CCCAAGGCTCCTCCTCACA-3' \\
& R: 5'-TTGAGGTCGGTCAGGAGAGTGA-3' \\
& F: 5'-CCTGGATACCGCAGCTAGGA-3' \\
& \\
\hline &
\end{tabular}

and then incubated with rabbit anti-53BP1 antibody (Cell Signaling) and mouse anti- $\gamma-\mathrm{H}_{2} \mathrm{AX}$ (Ser-139) antibody (Biolegend) at $4{ }^{\circ} \mathrm{C}$ overnight. The cells were washed with PBS with $0.1 \%$ Tween-20 for three times, and then stained with anti-rabbit IgG-Alexa Fluor 488 and anti-mouse IgG- Alexa Fluor 555 (Invitrogen) at room temperature for $1 \mathrm{~h}$, washed and mounted with DAPI Fluoromount-G (SouthernBiotech, Birmingham, AL). Images were acquired with a confocal laser-scanning inverted microscope (Leica Confocal, Model TCS sp8, Germany).

\section{ATM transfection}

Purified naive $\mathrm{CD}^{+}{ }^{+} \mathrm{T}$ cells from $\mathrm{HCV}$ patients were transfected with $2.5 \mu \mathrm{g}$ pcDNA3.1 (a gift from Adam Antebi $^{48}$, Addgene plasmid \# 52534), or pcDNA3.1(+) Flag-His-ATM wt (a gift from Michael Kastan ${ }^{49}$, Addgene plasmid \# 31985), or hATMS1981A mutant (a gift from Michael Kastan ${ }^{31}$, Addgene plasmid \# 32300), using the Human T Nucelofector Kit and Nucleofector I Device (LonzaLonza, Allendale, NJ). 24 h post transfection, GFP fluorescence was observed under microscope and the GFP expression level was measured by Flow Cytometry. $48 \mathrm{~h}$ post transfection, transfection efficiencies were monitored by flow cytometry measuring the frequency of $\mathrm{His}^{+}$cells. Ectopic ATM expression was detected by western blot. Active caspase-3, $\gamma \mathrm{H}_{2} \mathrm{AX}$, and IL-2 expressions were assessed in the His-positive cells by Flow Cytometry.

\section{Statistical analysis}

The data were summarized as mean \pm SEM or median with interquartile range and analyzed using Prism 7 software. Comparisons between two groups were made using independent Student's $t$-test, or paired $T$ test, and multiple comparisons test/least significant difference or Tukey's procedure, depending on the ANOVA $F$ test or by a nonparametric Mann-Whitney $U$-test. $P$ values $<0.05,<0.01$, or $<0.001$ were considered to be statistically significant or very significant, respectively.

\section{Acknowledgements \\ This work was supported by the National Institutes of Health grants R01DK093526, and R01Al114748 (to ZQY/JPM), and R15AG050456 (to JPM/ ZQY), and by a VA Merit Review Award INFA-016-15S (to ZQY/JPM). This publication is the result of work supported with resources and the use of facilities at the James $\mathrm{H}$ Quillen Veterans Affairs Medical Center. The contents in this publication do not represent the views of the Department of Veterans Affairs or the United States Government.}

\section{Author details \\ ${ }^{1}$ Center of Excellence in Inflammation, Infectious Disease and Immunity, James $\mathrm{H}$ Quillen College of Medicine, East Tennessee State University, Johnson City, TN 37614, USA. ²Department of Internal Medicine, Division of Infectious, Inflammatory and Immunologic Diseases, Quillen College of Medicine, ETSU, Johnson City, TN 37614, USA. ${ }^{3}$ Department of Infectious Diseases, Tangdu Hospital, the Fourth Military Medical University, Xi'an 710038, China. \\ ${ }^{4}$ Department of Biomedical Science, James H Quillen College of Medicine, East Tennessee State University, Johnson City, TN 37614, USA. 5 Department of Veterans Affairs, Hepatitis (HCV/HIV) Program, James H Quillen VA Medical Center, Johnson City, TN 37614, USA}

\section{Author contributions}

J.Z. performed most of the experiments and statistical analysis, X.D., P.Z., L.N.N., D.C., and L.W. participated in the acquisition of data. X.Y.W. and Z.D.M provided material and technical support. Y.Z., Z.J., Q.X., L.W., S.N., M.E.G, and J.P.M. offered intellectual input for interpretation and discussion of the findings. Z.Q.Y. obtained funding, supervised the project, and wrote the manuscript, with help of all other authors.

\section{Conflict of interest}

The authors declare that they have no conflict of interest.

Supplementary Information accompanies the paper at (https://doi.org/ 10.1038/s41421-018-0015-4).

Received: 2 November 2017 Accepted: 21 December 2017 Published online: 10 April 2018

\section{References}

1. Park, S. H. \& Rehermann, B. Immune responses to HCV and other hepatitis viruses. Immunity 40, 13-24 (2014).

2. Yao, Z. Q. \& Moorman, J. P. Immune exhaustion and immune senescence two distinct pathways for HBV vaccine failure during HCV and/or HIV infection. AITE 61, 193-201 (2013). 
3. Shi, L., et al. KLRG1 impairs CD4+ $T$ cell responses via $p 16^{\text {ink4a }}$ and $p 27^{\text {kip1 }}$ pathways: role in hepatitis $B$ vaccine failure in individuals with hepatitis $C$ virus infection. J. Immunol. 192, 649-657 (2014).

4. Li, G., et al. HCV induced reduction in miR-181a impairs CD4+T cell responses via over-expression of DUSP6. Hepatology 61, 1163-1173 (2014).

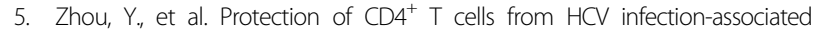
senescence via $\triangle$ Np63-miR181a-Sirt1 pathway. J. Leukoc. Biol. 100, 1201-1211 (2016).

6. Hoare, M., et al. CD4+T-lymphocyte telomere length is related to fibrosis stage, clinical outcome and treatment response in chronic hepatitis $\mathrm{C}$ virus infection. J. Hepatol. 53, 252-260 (2010).

7. Qi, Q., Zhang, D. W., Weyand, C. M. \& Goronzy, J. J. Mechanisms shaping the naive $T$ cell repertoire in the elderly - Thymic involution or peripheral homeostatic proliferation? Exp. Gerontol. 54, 71-74 (2014).

8. Krammer, P. H., Arnold, R. \& Lavrik, I. N. Life and death in peripheral T cells. Nat. Rev. Immunol. 7, 532-542 (2007).

9. Yonkers, N. L., Sieg, S., Rodriguez, B. \& Anthony, D. D. Reduced naive CD4 T cell numbers and impaired induction of CD27 in response to $T$ cell receptor stimulation reflect a state of immune activation in chronic hepatitis $C$ virus infection. J. Infect. Dis. 203, 635-645 (2011).

10. Tao, S., et al. Characteristics and PD-1 expression of peripheral CD4 + CD127loCD25hiFoxP3+Treg cells in chronic HCV infected-patients. J. Virol. 8, 279-288 (2011).

11. Moorman, J. P., et al. Tim-3 controls regulatory and effect T cell balance during HCV Infection. J. Immunol. 189, 755-766 (2012).

12. Barathan, M., et al. Peripheral loss of CD8(+) CD161(++) TCRVa7.2(+) mucosalassociated invariant $\mathrm{T}$ cells in chronic hepatitis $\mathrm{C}$ virus-infected patients. Eur. J. Clin. Invest. 46, 170-180 (2016).

13. Barathan, M., et al. Increased frequency of late-senescent T cells lacking CD127 in chronic hepatitis C disease. Eur. J. Clin. Invest. 45, 466-474 (2015).

14. Ferrando-Martínez, S., et al. HIV infection-related premature Immunosenescence: high rates of immune exhaustion after short time infection. Curr. HIV Res. 9, 289-294 (2011).

15. Kramer, E. S., Hofmann, C., Smith, P. G., Shiffman, M. L. \& Sterling, R. K. Response to hepatitis $A$ and $B$ vaccine alone or in combination in patients with chronic hepatitis C virus and advanced fibrosis. Dig. Dis. Sci. 54, 2016-2025 (2009).

16. Moorman, J. P., et al. Impaired hepatitis B vaccine responses during chronic hepatitis $C$ infection: involvement of the PD-1 pathway in regulating $C D 4^{+} \mathrm{T}$ cell responses. Vaccine 29, 3169-3176 (2011).

17. Wang, J. M., et al. Tim-3 alters the balance of $\mathrm{LL}-12 / \mathrm{LL}-23$ and drives $\mathrm{TH} 17$ cells: Role in hepatitis B vaccine failure during hepatitis C infection. Vaccine 31, 2238-2245 (2013).

18. Malaspina, A., et al. Compromised B cell responses to influenza vaccination in HIV-infected individuals. J. Infect. Dis. 191, 1442-1450 (2005).

19. Rodriguez-Barradas, M. C., et al. Response of human immunodeficiency virusinfected patients receiving highly active antiretroviral therapy to vaccination with 23-valent pneumococcal polysaccharide vaccine. Clin. Infect. Dis. 37, 438-447 (2003).

20. Fujii, H., Shao, L., Colmegna, I., Goronzy, J. J. \& Weyand, C. M. Telomerase insufficiency in rheumatoid arthritis. Proc. Natl. Acad. Sci. USA 106, 4360-4365 (2009).

21. Wang, Z., et al. Characterization of oxidative guanine damage and repair in mammalian telomeres. PLoS. Genet. 6, e1000951 (2010).

22. Bartek, J. \& Lukas, J. DNA damage checkpoints: from initiation to recovery or adaptation. Curr. Opin. Cell. Biol. 19, 238-245 (2007).

23. Uziel, T. et al. Requirement of the MRN complex for ATM activation by DNA damage. EMBO J. 22, 5612-5621 (2003).

24. Dupre, A., Boyer-Chatenet, L. \& Gautier, J. Two-step activation of ATM by DNA and the Mre11-Rad50-Nbs1 complex. Nat. Struct. Mol. Bio 13, 451-457 (2006).

25. Shiloh, Y. Ataxie-telagiectasia and the Nijmegen breakage syndrome: related disorders but genes apart. Annu. Rev. Genet. 31, 635-662 (1997).
26. Awasthi, P., Foiani, M. \& Kumar, A. ATM and ATR signaling at a glance. J. Cell Sci. 128, 4255-4262 (2015).

27. Rothkamm, K. et al. DNA damage foci: Meaning and significance. Environ. Mol. Mutagen. 56, 491-504 (2015).

28. Takai, H., Smogorzewska, A. \& de Lange, T. DNA damage foci at dysfunctional telomeres. Curr. Biol. 13, 1549-1556 (2003).

29. Yao, Z. Q. et al. T cell dysfunction by hepatitis C virus core protein involves PD1/PD-L1 signaling. Viral Immunol. 20, 276-287 (2007).

30. El Awady, M. K, et al. Circulating viral core and E1 antigen levels as supplemental markers for HCV chronic hepatitis. J. Virol. 3, 67 (2006).

31. Bakkenist, C. J. \& Kastan, M. B. DNA damage activates ATM through intermolecular autophosphorylation and dimer dissociation. Nature 421, 499-506 (2003).

32. Lee, J. H. \& Paull, T. T. ATM activation by DNA double-strand breaks through the Mre11-Rad50-Nbs1 complex. Science 308, 551-554 (2005).

33. Lavin, M. F. ATM and the Mre 11 complex combine to recognize and signal DNA double-strand breaks. Oncogene 26, 7749-7758 (2007).

34. So, S., Davis, A. J. \& Chen, D. J. Autophosphorylation at serine 1981 stabilizes ATM at DNA damage sites. J. Cell Biol. 187, 977-990 (2009).

35. Li, Y., et al. Deficient activity of the nuclease MRE11 induces T cell aging and promotes arthritogenic effector functions in patients with rheumatoid arthritis. Immunity 45, 1-14 (2016).

36. Guo, Z., Deshpande, R. \& Paull, T. T. ATM activation in the presence of oxidative stress. Cell Cycle 9, 4805-4811 (2010).

37. Guo, Z., Kozlov, S., Lavin, M. F., Person, M. D. \& Paull, T. T. ATM activation by oxidative stress. Science 330, 517-521 (2010).

38. Alexander, A., et al. ATM signals to TSC2 in the cytoplasm to regulate mTORC1 in response to ROS. Proc. Natl. Acad. Sci. USA 107, 4153-4158 (2010).

39. Alexander, A., Kim, J. \& Walker, C. L. ATM engages the TSC2/mTORC1 signaling node to regulate autophagy. Autophagy 6, 672-673 (2010).

40. Alexander, A. \& Walker, C. L. Differential localization of ATM is correlated with activation of distinct downstream signaling pathways. Cell Cycle 9, 3685-3686 (2010).

41. Yao, Z. Q., Eisen-Vandervelde, A., Ray, S. \& Hahn, Y. S. HCV core/gC1qR interaction arrests $\mathrm{T}$ cell cycle progression through stabilization of the cell cycle inhibitor p27kip1. Virology 314, 271-282 (2003).

42. Henle, E. S. et al. Sequence-specific DNA cleavage by Fe2+-mediated fenton reactions has possible biological implications. J. Biol. Chem. 274, 962-971 (1999).

43. Petersen, S., Saretzki, G. \& von Zglinicki, T. Preferential accumulation of singlestranded regions in telomeres of human fibroblasts. Exp. Cell Res. 239, 152-160 (1998).

44. Herbeuval, J. P., et al. Regulation of TNF-related apoptosis-inducing ligand on primary $\mathrm{CD}^{+} \mathrm{T}$ cells by HIV-1: role of type I IFN-producing plasmacytoid dendritic cells. Proc. Natl. Acad. Sci. USA 102, 13974-13979 (2005).

45. Stacey, M. A., et al. The antiviral restriction factor IFN-induced transmembrane protein 3 prevents cytokine-driven CMV pathogenesis. J. Clin. Invest. 127, 1463-1474 (2017)

46. Kadereit, $\mathrm{S}$. et al. Negative regulation of $\mathrm{CD} 8+\mathrm{T}$ cell function by the IFNinduced and double-stranded RNA-activated kinase PKR. J. Immunol. 165 6896-6901 (2000).

47. Randall, R. E. \& Goodbourn, S. Interferons and viruses: an interplay between induction, signaling, antiviral responses and virus countermeasures. J. Gen. Virol. 89(Pt 1), 1-47 (2008).

48. Horn, M., et al. DRE-1/FBXO11-dependent degradation of BLMP-1/BLIP-1 governs C. elegans developmental timing and maturation. Dev. Cell. 28, $697-710$ (2014)

49. Canman, C. E., et al. Activation of the ATM kinase by ionizing radiation and phosphorylation ofp53. Science 281, 1677-1679 (1998). 